Western University Scholarship@Western

Economic Policy Research Institute. EPRI Working

Papers

Economics Working Papers Archive

2008

2008-6 Non-agricultural Employment

Determinants and Income Inequality

Decomposition

Xiaoyun Liu

Terry Sicular

Follow this and additional works at: https://ir.lib.uwo.ca/economicsepri_wp

Part of the Economics Commons

Citation of this paper:

Liu, Xiaoyun, Terry Sicular. "2008-6 Non-agricultural Employment Determinants and Income Inequality Decomposition." Economic Policy Research Institute. EPRI Working Papers, 2008-6. London, ON: Department of Economics, University of Western Ontario (2008). 


\title{
Non-agricultural Employment Determinants and Income Inequality Decomposition
}

\author{
by
}

Xiaoyun Liu and Terry Sicular

Working Paper \# 2008-6

December 2008

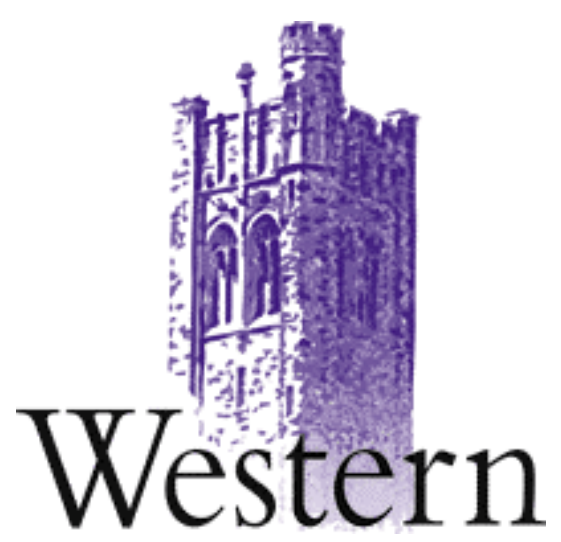

\section{RBC Financial Group \\ Economic Policy Research Institute EPRI Working Paper Series}

\author{
Department of Economics \\ Department of Political Science \\ Social Science Centre \\ The University of Western Ontario \\ London, Ontario, N6A 5C2 \\ Canada
}

This working paper is available as a downloadable pdf file on our website http://economics.uwo.ca/centres/epri/ 


\title{
Non-agricultural Employment Determinants and Income Inequality Decomposition
}

\author{
Xiaoyun Liu* \\ Associate Professor, College of Humanity and Development, China Agricultural University \\ Terry Sicular \\ Professor, Department of Economics, University of Western Ontario
}

\begin{abstract}
:
Non-agricultural income has become an important source of rural household income and has brought with a wide inequality in rural China. This paper investigates the determinants of non-agricultural employment as well as non-agricultural income and then assesses the contribution of these determinants to income inequality with the Chinese Academy of Social Science 2003 survey data and a three-step decomposition approach. Our results indicate that education inequality accounts for $9 \%$ and $36 \%$ wage and self-employment income inequality respectively which implies that education inequality plays substantial roles in non-agricultural income inequalities. The community characteristics collectively accounts for $46 \%$ and $32 \%$ of the wage and self-employment income inequality respectively which in turn suggests that regional development is of great importance in the determination of non-agricultural income inequality.
\end{abstract}

Key words: non-agricultural income, employment, Inequality

JEL: J23, J43, D63

\footnotetext{
* liuxy@cau.edu.cn. The author would like thank John Whalley and Aldo Colussi (the University of Western Ontario), John Knight (University of Oxford), Fang Cai (China Academy of Social Science), Shi Li( Beijing Normal University) and participants at the 7th Seminar of YCSPRN for their helpful comments on earlier drafts. This study is funded by the Poverty Research Network and is gratefully acknowledged.
} 


\section{Introduction}

Dramatic changes have taken place in the pattern of rural employment in China. Statistics indicates that the structure of income for rural households has changed substantially in recent decades (National Bureau of Statistics of China, 2005), and that income from non-agricultural pursuits has increased substantially in importance. Non-agricultural income contributed $48 \%$ of total income of rural households in China in 2005, compared with only $29 \%$ in 1990. Concurrently, the number of rural laborers engaged in non-agricultural employment doubled and in agricultural employment declined during 1990-2005. During this period, China also experienced rapid poverty reduction along with growing income inequality.

Changes in China's rural household income structure and employment pattern have been found to have impacts on inequality and poverty as suggested by the literature such as Benjamin, Brandt and Giles (2003), Cai(2005), Du(2005), Khan and Riskin (1998, 2005), Tsui (1998), Knight and Song (2003), and Zhao and Li (1999). This literature generally suggest that agricultural and non-agricultural income have different impacts on inequality in China and that changes in the composition of income account for the changes in income inequality. It has been noted that wage income has increased sharply and wage income is still a disequalizing source of income. $\mathrm{Du}$ (2005) assesses the impacts of migration on rural income and finds the impact of migration on poverty is small because most of the poor do not migrate. Cai (2005) also offers explanations for the rising inequality along with increase migration in China. Several studies such as Sicular (2007) divide rural households by region and decompose income inequality into inter-regional and within-regional components. They arrive at the conclusion that the regional inequality increased and regional differences play an important role in the overall inequality.

Similar studies exist for other countries. For examples, Richard (2001) uses a decomposition approach to examine the impacts of different sources of income on poverty and inequality in rural Egypt and Jordan. Non-agricultural income is found to reduce poverty and improve income distribution in Egypt. In Jordan, however, non-agricultural income goes mainly to the rich and thus tends to increase rural inequality. One relevant study on rural Ghana and Uganda finds that non-farm earnings contribute to rising inequality, but lower income groups also benefit due to the strong overall growth in non-farm earnings (Canagarajah, Newman, and Bhattamishra, 2001). Reardon (1997) finds that non-farm income share is higher for rich households than that for poorer households in Africa. The usual reasoning for why the relatively well-off are more likely to be found working in non-farm activities is that these activities require a minimum amount of capital and education in order to be successful. 
Some studies go further to investigate the determinants of rural households' income and the causes of inequality in rural China (Meng and Wu, 1998; Wan, 2004). Sicular and Zhao (2002) examined earnings and labor distribution using data for 1997 and find the returns to non-agricultural labor hours were higher than that for agricultural labor hours. Their results indicate that poorer households not only have less off-farm employment, but also lower returns to their work. Wan and Zhou (2005) used a regression-based decomposition framework to study inequality in rural China with household survey data. They find geography, capital, and farming structure have different effects on income inequality.

In summary, China's rural employment pattern and thus income sources play a substantial role in inequality and poverty. Since non-agricultural income has been becoming more and more substantial in rural household income and inequality, investigating the determinants of China's rural employment pattern and income is essential to understanding rural inequality and poverty. Assessing these determinants and decomposing inequality is thus the goal of this paper.

In contrast to much of the current literature on China's rural employment participation and income determination which uses individual data, this paper employs the classical household model in which household instead of individual decision making is examined, For the analysis we use the China Household Income Project (CHIP) survey data and a three-step decomposition approach. In this paper we differentiate two different types of non-agricultural activities, namely, wage employment (WE) and non-agricultural self-employment (SE). Our results indicate that education inequality accounts for $9 \%$ and 36\% wage and self-employment income inequality, respectively, which implies that education inequality plays substantial roles in non-agricultural income inequalities. The community characteristics collectively accounts for $46 \%$ and $32 \%$ of the wage and self-employment income inequality, respectively, which in turn suggests that regional development is of great importance in the determination of non-agricultural income inequality.

The rest of the paper is organized as follows. Section two describes the three-step approach used to investigate the determinants of the two different types of non-agricultural employment participation and income inequality decompositions. Section 3 describes the data. Regression results are offered in section 4 , and section 5 concludes.

\section{Methodology}


We use a three-step decomposition approach to assess the determinants of non-agricultural employment participation, income, and income inequality. We will first use a bi-probit rural household model of to examine the determinants of participation in wage employment and self-employment. We then estimate an income model using the inverse Mills ratio calculated from the bi-probit regression to correct for sample selection bias ${ }^{1}$. We then use a regression-based decomposition approach to conduct an inequality decomposition. The above mentioned models and decomposition techniques are elaborated as follows.

\subsection{Labor Participation Model}

According to the classical rural household model, labor supply to different types of work is jointly determined and so should be estimated simultaneously (Singh, 1986). Our data indicate that less than $2 \%$ of rural households are not involved in any kind of agricultural work, so we only examine the determinants of participation in wage employment and self-employment. Here a bi-probit model will be used to estimate the participation probability of wage employment and non-agricultural self-employment. This approach allows for the interactions between these two types of choices. The bi-probit model can also be used to assess the impacts of different determinants on job selection. Explanatory variables include household and community characteristics.

The bi-probit model takes the following form,

$$
\begin{aligned}
& Y_{i}^{*}=X \quad \beta_{i}+\mu_{i} \\
& P_{i}=1, \quad \text { if } \quad Y_{i}^{*}>0 \\
& P_{i}=0, \quad \text { otherwise }
\end{aligned}
$$

Where $i=W E$ or $S E ; \beta$ is the coefficient vector; $Y_{i}^{*}$ represents the unobserved labor supply of household's wage employment. If we consider the household as the decision-making unit, labor supply of WE and SE will be a function of some relevant variables as equation (1). In rural China agricultural income, SE income and WE income are typically pooled so that the household instead of the individual is the relevant unit of analysis. $\mathrm{P}_{\mathrm{i}}$ is a work participation indicator and $\mathrm{X}$ is a vector of independent variables that includes household characteristics, village characteristics, and regional characteristics. $\mathrm{u}_{\mathrm{i}}$ is the disturbance term with mean of zero. The variance-covariance matrix of $\left(\mathrm{u}_{1}, \mathrm{u}_{2}\right)$ has values of 1 on

\footnotetext{
${ }^{1}$ Here we follow Heckman-two-stag approach to dealing with self-selection bias. However it is argues that Heckman's estimator may be inefficient due to possible co-linearity problem (Puhani, 2000). Fortunately, appropriate instrument variables like children, political status and household wealth which affect selection but not in the outcome equations are available in the research, which can solve this problem. Moreover, we find no collinearity present in the data.
} 
the leading diagonal and correlations $\varrho_{j \mathrm{k}}=\varrho_{\mathrm{kj}}$ as off-diagonal elements. $\varrho_{\mathrm{jk}}=0$ means $\mathrm{Y}_{\mathrm{j}}{ }^{*}$ and $\mathrm{Y}_{\mathrm{k}}{ }^{*}$ are not correlated with each other. A household chooses to engage WE or/and SE when labor supply $\mathrm{Y}_{\mathrm{i}}^{*}$ exceeds zero.

\subsection{Income Model}

The second step of the analysis is to examine the determinants of wage and self-employment income. Most studies on rural income construct a total household income equation pooling agricultural income and non-agricultural income sources together. In this paper we will examine wage and self-employment income separately, with correction for the sample selection bias.

The bi-probit regression (Equation 1) produces the inverse Mills ratio (IMR), which we use to correct for the sample selection problem in the wage and self-employment income models.

Independent variables include household characteristics and community characteristics and take the following form:

$$
\ln Y_{i}=\alpha_{0}+\sum_{k=1}^{K} \alpha_{k} X_{k}+\varepsilon
$$

Here $\ln \mathrm{Y}_{\mathrm{i}}$ is $\log$ annual earnings from activity $\mathrm{i}(\mathrm{i}=\mathrm{WE}, \mathrm{SE})$. Explanatory variables include physical capital investment, land, labor, education and community characteristics as in the literature (Meng and Wu, 1998, Morduch and Sicular, 2000, Zhang et al, 2001).

\subsection{Regression-based decomposition of inequality}

Regression-based decomposition of inequality is used in the third step to decompose the contribution of various factors to income inequality. Applications of this method to China include Morduch and Sicular(2002), Fields and Yoo (2000), and Wan (2004). Inspired by inequality decomposition by income source (Shorrocks, 1999), Morduch and Sicular (2002) proposed a regression-based decomposition method and compared the decomposition for different inequality indexes. Yue et al. (2008) use this approach to explain incomes and inequality in China and find that education and location are the largest contributors to income inequality. Another approach developed by Shorrocks (1999), the 'Shapley Value Decomposition', is used by Wan and Zhou (2005) to decompose income inequality in rural China. Their results showed that capital input and farming structure were the most significant factors explaining income inequality. We decompose the wage and self-employment income inequality 
following Wan's (2004) method².

\section{Data}

The data come from the CHIP survey conducted in 2003 yielding data for the year 2002. The dataset contains information on household composition, income, employment, and education and other related variables. In this study we use the rural sub-sample of the CHIP survey consisting of 9200 households. These rural households are located in 120 different counties in 22 provinces. Table 1 offers a brief summary of the locations of the rural households. Descriptive statistics of the explanatory variables used in the regressions are listed in Table 2.

In our sample 37\% of rural household income comes from agricultural work, 30\% from wage employment, $11 \%$ from non-agricultural self-employment, and $22 \%$ from other sources. Of all rural households in the sample, only about $1.7 \%$ does not engage in agricultural work, so in this research we will only study participation in wage employment and non-agricultural self-employment. Our sample also indicates that $78 \%$ of rural households were engaged in wage employment and $53 \%$ engaged in self-employment jobs.

Rural households with participation in neither wage nor self-employment are associated with the highest agricultural income (RMB 2152.58) and the lowest income per capita (RMB 2817.67). Households that participated in both the two types of non-agricultural employment are associated with the highest income per capita (RMB 3955.78). These results imply that participation in non-agricultural employment is correlated positively with household income per capita.

We further divide the 9200 rural households into deciles according to income and find that higher income rural households are associated with higher non-agricultural employment participation and thus a higher share of household income from non-agricultural employment income. Non-agricultural employment income accounts for around $60 \%$ of total rural household income for the highest decile group, as compared to less than $30 \%$ for the lowest decile group.

\section{Regression and Decomposition Results}

\footnotetext{
${ }^{2}$ Compared with earlier methods, the procedure of Wan (2004) combines the advantage of Shapley value approach of Shorrocks (1999), it does not impose any restrictions on regression model and can be applied to any inequality measure. Detailed discussion can be seen in Wan (2002).
} 


\subsection{Regression Results of Labor Participation and Income Model}

The regression results of the bi-probit model are reported in Table 3. The hypothesis of non-correlation between WE and SE is rejected, implying the need to use simultaneous estimation of the bi-probit model.

The estimation results indicate that age has a significant negative effect on rural household participation in both wage and self-employment, which implies that with the rise of the average age of rural households, participation in both wage employment and self-employment declines. Education level is found to have a significantly positive impact on wage employment participation but no significant impact on household self-employment participation. This finding is similar to that in other studies such as Knight (2003). Possible explanations for the absence of an effect of education on SE participation could be the specific characteristics of SE. Many SE such as handicrafts need training but not formal education.

The ratio of children in the household has a significant negative effect on participation in WE but not SE. A possible explanation could be that the having children (less than 11 years old) hinders household members' ability to leave the villages to earn wage income. Self-employment is often run out of the home by families and thus this work can be combined more easily with childcare. Households with more working-age labor tend to have higher participation in wage employment and lower participation in self-employment.

The results also indicate that having a Chinese Community Party member in the household significantly increases the probability of wage employment while reducing that of self-employment. Moreover, having relatives in urban areas also increases participation in both wage and non-agricultural self-employment. This evidence reinforces the importance of social networks for rural household non-agricultural income earnings.

The amount of arable land area per capita reduces participation rates in both wage employment and self-employment. Wealthy households (evaluated by average household income in the last 4 years) are associated with higher participation in both wage employment and self-employment. Knight (2003) argues that household wealth may help to provide the funds and the security needed for migration, and it may provide the resources for non-farm self-employment. These results, then, show that both physical capital and social capital can have significant effects on employment selection. 
The significant and positive coefficients of community characteristics suggest that more developed communities as indicated by a high rate of labor migration or of TVE employment are usually associated with higher rates of participation in wage employment. The probabilityof participation in self-employment tends to decline for households in villages with higher migration ratios. In communities with more households engaged in self-employment, the probability of household self-employment participation is higher, but that of wage employment is lower.

We estimate the income equations for wage income and self-employment income models and use the IMRs from the bi-probit models to correct for sample selection bias. Table 4 reports the results. The IMRs are significant, indicating the presence of sample selection bias. From the results one can observe that education has a significantly positive effect on both wage and self-employment income. Education may not affect self-employment participation, but it does affect self-employment income once the rural household participates in self-employment business.

\subsection{Decomposition Results}

The regression-based decompositions of inequality of wage income and of self-employment income are reported in Table 5. The results show that household education accounts for $8 \%$ and $36 \%$ of wage and self-employment income inequality, respectively. Community characteristics, including local wage levels and regional dummies, together account for $46 \%$ of inequality in wage income. Physical capital investment accounts for over $30 \%$ of self-employment income inequality, and regional dummies contribute $32 \%$ of self-employment income inequality.

We also conduct agricultural income inequality decompositions and the results indicate that education accounts for merely of $2 \%$ of agricultural income inequality, while land per capita (52\%) and agricultural capital (28\%) together explain $80 \%$ of the agricultural income inequality. These results suggest that education inequality contributes more to non-agricultural than to agricultural income inequality. This finding is similar to the conclusions of Wan (2005) and Yue et al. (2008), who point out that inequality of education has become an important determinant of household total income inequality. Because non-agricultural income is the largest component of rural household income, inequality of education becomes an important factor in rural income inequality.

\section{Concluding Remarks}


This paper investigates the determinants of non-agricultural employment as well as non-agricultural income and then assesses the contribution of these determinants to rural inequality. The analysis makes use of the CHIP 2002 household survey data and a three-step decomposition approach. We first use a bi-probit model to examine participation in the two types of non-agricultural employment, wage employment and self-employment. Income models of the two types of non-agricultural employment are then estimated, with correction for sample selection bias. Regression-based decomposition approach is used to decompose inequality for the two types of non-agricultural income as well as for agricultural income.

Our results reveal that inequality in education accounts for $9 \%$ and $36 \%$ wage and self-employment income inequality, respectively; however, it has no impact on agricultural income inequality. In China's current system, provincial and local governments are responsible for education. Because of differences in economic development and fiscal resources, local education expenditures are highly uneven. For example, in 1999 the education expenditure per elementary school student in rural Shanghai was eight times that in rural Guizhou. If inequality of education enlarges, then income inequality would also increase. Although compulsory primary education is now free in China, higher-level education is still expensive for the rural poor, and policies providing financial aid to rural poor children may be beneficial.

The results also indicate that community characteristics collectively account for large shares of wage and self-employment income inequality. This finding suggests that community development is of great importance in the determination of non-agricultural income inequality and highlights the importance of policies to promote development in those less developed regions.

Since non-agricultural income has been becoming more important as a source of income for China's rural households, promoting development in less developed regions (especially of those in the western part of China) and also widening access to education are increasingly key in China's fight against inequality. 


\section{References}

[1] Benjamin, D., L. Brandt. and J. Giles, The Evolution of Income Inequality in Rural China, working paper, 2003

[2] Cai F., Why rural-urban migration has not brought down income gap between sectors, Discussion paper, Institute of Population and Labor Economics, 2005.

[3] Christofides, L. N. and Pashardes P., Self/paid-employment, public/private sector selection, and wage differentials, Labor Economics 9, 737-762, 2002.

[4] De Brauw A., Huang J. and etc, the evolution of China's rural labor markets during the reforms, Journal of

Comparative Economics, Vol. 30, 329-353, 2002.

[5] Du Y., Albert Park, S. Wang, Migration and rural poverty in China, Journal of Comparative Economics, No. 33, pp688-709, 2005.

[6] Fields, G., G. Yoo, Falling labor income inequality in Korea’s economic growth: patterns and underlying causes, Review of Income and Wealth (46) 2, 139-159, 2000

[7] Khan, A. R. and Carl Riskin, Income and Inequality in China, China Quarterly, June, 1998.

[8] Khan, A.R. and Carl Riskin, China’s household income and its distribution, 1995 and 2002, China Quarterly, June. 2005.

[9] Knight J. and Song L., 2003, Chinese peasant choices: migration, rural industry or farming, Oxford Development Studies, Vol. 31, No. 2, 123-147, 2003

[10] Meng X. and Wu H., Household income determination and regional income differential in rural China, Asian Economic Journal, 1998, Vol.12 No.1, 1998

[11] Morduch, J. and Sicular, T., Rethinking inequality decomposition, with evidence from rural china. The Economic Journal, 112(476):93\{106(14), 2002

[12] National Bureau of Statistics of China, 2005, Zhongguo Tongji Nianjian (China statistical yearbook). State Statistical Bureau Press, 2005

[13] Puhani, P.A., The Heckman Correction for Sample Selection and Its Critique, Journal of Economic Surveys 14(1):53-68, 2000

[14] Richard H. Adams, Nonfarm Income, Inequality and Poverty In Rural Egypt and Jordan, World Bank, working paper, 2001

[15] Shorrocks, Anthony F., Decomposition procedures for distributional analysis: a unified framework based on the Shapley value, Department of Economics, University of Essex, 1999

[16] Sicular Terry and Y.H. Zhao, Employment, earnings and poverty in rural China: a microeconomic analysis, Paper Prepared for the Workshop on China’s WTO Accession, June 28-29, 2002.

[17] Sicular, Terry, Yue Ximing, Gustafsson, Björn, and Li Shi, The Urban-Rural Gap and Income Inequality in China, Review of Income and Wealth 53, 1 (2007): 93-126.

[18] Singh, I., L. Squire and J. Strauss, Agricultural Household Models - Extensions, Applications and Policy, Baltimore, The Johns Hopkins University Press, 1986.

[19] Tsui, Kai-yuan, Trends and inequalities of rural welfare in China: evidence from rural households in Guangdong and Sichuan, Journal of Comparative Economics 26: 783-804, 1998.

[20] Wan, G. H. and Z. Zhou, Income inequality in rural China: regression-based decomposition using household data, Review of Development Economics, 9(1), 107-120, 2005

[21] Wan, G. H., Accounting for income inequality in rural China: a regression-based approach, Journal of Comparative Economics 32 (2) : 348-363, 2004.

[22] Wan, G. H., Regression-Based Inequality Decomposition: Pitfalls and a Solution Procedure, UNUWIDER Discussion Paper, 2002 
[23] Yue Ximing, Sicular, Terry, Li Shi and Gustafsson, Björn, Explaining Incomes and Inequality in China. In Gustafsson, Björn, Li Shi and Terry Sicular (Editors). Inequality and Public Policy in China. New York: Cambridge University Press. 2008.

[24] Zhang, L.X., S. Rozelle, and J. Huang, Off-Farm jobs and on-Farm work in periods of boom and bust in rural China, Journal of Comparative Economics, 29:505-26. 2001.

Table 1: CHIP Rural Sample Summary

\begin{tabular}{|c|c|c|}
\hline Provinces & Number of Housholds & Number of Counties \\
\hline Beijing & 160 & 2 \\
\hline Hebei & 370 & 5 \\
\hline Shanxi & 400 & 6 \\
\hline Liaoning & 450 & 6 \\
\hline Jilin & 480 & 6 \\
\hline Jiangsu & 440 & 5 \\
\hline Zhejiang & 520 & 6 \\
\hline Anhui & 440 & 5 \\
\hline Jiangxi & 430 & 6 \\
\hline Shandong & 630 & 7 \\
\hline Henan & 530 & 7 \\
\hline Hubei & 520 & 6 \\
\hline Hunan & 450 & 5 \\
\hline Guangdong & 530 & 5 \\
\hline Sichuan & 500 & 6 \\
\hline Guizhou & 400 & 6 \\
\hline Yunnan & 260 & 5 \\
\hline Shannxi & 370 & 6 \\
\hline Gansu & 320 & 5 \\
\hline Guangxi & 400 & 5 \\
\hline Chongqin & 200 & 2 \\
\hline Xinjiang & 400 & 8 \\
\hline
\end{tabular}

Source: CHIP 2002 survey data

Table 2: Descriptive Statistics for Variables

Mean Standard

Deviation

Household Characteristics

age

education

kid

labor

party
Average age of working-age household members(years)

The maximum education level in household (years)

The ratio of children under 11 to household size

The number of working-age household members

Whether the household contains any Party members, 1 : yes and 0:

no.

$40.242 \quad 7.880$

$8.972 \quad 2.160$

$0.188 \quad 0.304$

$2.977 \quad 1.049$

$0.199 \quad 0.400$ 


\begin{tabular}{|c|c|c|c|}
\hline ethnic & $\begin{array}{l}\text { Whether the household contains an ethnic minority household } \\
\text { member, } 1 \text { : yes and } 0 \text { : no. }\end{array}$ & 0.131 & 0.338 \\
\hline land & Contracted arable land per capita (mu?) & 2.095 & 1.682 \\
\hline income & Average income in 1998-2001 $(\log )$ & 7.515 & 0.565 \\
\hline investment & Investment $(\log )$ & 7.106 & 2.451 \\
\hline urban & $\begin{array}{l}\text { Whether the household has a relative living in a city, 1: yes and } 0 \text { : } \\
\text { no. }\end{array}$ & 0.559 & 0.497 \\
\hline \multicolumn{4}{|c|}{ Community Characteristics } \\
\hline migration & The ratio of the village labor force migrating out & 0.229 & 0.174 \\
\hline tve & The ratio of the labor force working in TVEs & 0.080 & 0.181 \\
\hline se & The ratio of households with non-agricultural self-employment & 0.049 & 0.063 \\
\hline distance & Distance to the nearest bus? station (in $\log$ ) & 1.049 & 1.002 \\
\hline wage & The average daily wage of labor in the village & 2.805 & 0.302 \\
\hline
\end{tabular}

Source: CHIP 2002 survey data

Table 3: Bi-Probit Estimation Results for Employment Participation

\begin{tabular}{|c|c|c|c|c|}
\hline & \multicolumn{2}{|c|}{ Wage Employment } & \multicolumn{2}{|c|}{$\begin{array}{l}\text { Non-agricultural } \\
\text { self-employment }\end{array}$} \\
\hline & Coef. & $\mathrm{P}>\mathrm{z}$ & Coef. & $\mathrm{P}>\mathrm{Z}$ \\
\hline \multicolumn{5}{|c|}{ Household characteristics } \\
\hline age & -0.016 & 0.000 & -0.011 & 0.000 \\
\hline education & 0.014 & 0.099 & -0.012 & 0.128 \\
\hline kid & -0.115 & 0.063 & 0.074 & 0.203 \\
\hline labor & 0.106 & 0.000 & -0.006 & 0.687 \\
\hline party & 0.176 & 0.000 & -0.126 & 0.002 \\
\hline ethnic & -0.251 & 0.000 & -0.069 & 0.172 \\
\hline land & -0.105 & 0.000 & -0.080 & 0.000 \\
\hline income & 0.199 & 0.000 & 0.282 & 0.000 \\
\hline urban & 0.065 & 0.066 & 0.100 & 0.002 \\
\hline \multicolumn{5}{|c|}{ Community Characteristics } \\
\hline migration & 1.281 & 0.000 & -0.242 & 0.010 \\
\hline tve & 0.585 & 0.000 & 0.021 & 0.823 \\
\hline se & -0.632 & 0.026 & 1.075 & 0.000 \\
\hline distance & -0.060 & 0.001 & 0.013 & 0.422 \\
\hline wage & -0.098 & 0.122 & -0.084 & 0.142 \\
\hline east & 0.138 & 0.001 & -0.006 & 0.878 \\
\hline west & 0.102 & 0.029 & 0.121 & 0.005 \\
\hline constant & -0.405 & 0.216 & -1.541 & 0.000 \\
\hline /athrho & -0.186 & 0.000 & & \\
\hline Log likelihood & -7886.8714 & & & \\
\hline No. of observations & 6826 & & & \\
\hline
\end{tabular}


Table 4: Regression Results of Income Models

\begin{tabular}{lrrrr}
\hline & \multicolumn{2}{l}{ Wage Income } & \multicolumn{2}{c}{ Self-Employment Income } \\
\hline \multicolumn{2}{l}{ Coef. } & $\mathrm{p}>|\mathrm{t}|$ & Coef. & $\mathrm{p}>|\mathrm{t}|$ \\
age & 0.003 & 0.091 & 0.012 & 0.001 \\
education & 0.039 & 0.000 & 0.075 & 0.000 \\
labor & 0.035 & 0.008 & 0.000 & 0.986 \\
investment & - & - & 0.071 & 0.000 \\
wage & 0.501 & 0.000 & 0.312 & 0.000 \\
east & 0.287 & 0.000 & 0.106 & 0.062 \\
west & -0.206 & 0.000 & -0.424 & 0.000 \\
IMR & -1.860 & 0.000 & -2.430 & 0.000 \\
constant & 6.686 & 0.000 & 7.297 & 0.000 \\
$\mathrm{R}^{2}$ & 0.22 & & 0.17 & \\
No. of observations & 5119 & & 2551 & \\
\hline
\end{tabular}

Table 5: Inequality Decomposition of Income Inequality (\%)

\begin{tabular}{lrrrr}
\hline \multicolumn{2}{c}{ Wage Income } & \multicolumn{2}{c}{ Self-Employment Income } \\
\hline & Gini Coefficient & $\begin{array}{c}\text { Contribution } \\
\text { Gini Coefficient }\end{array}$ & $\begin{array}{r}\text { Contribution } \\
\text { age }\end{array}$ \\
education & 0.003 & 1.104 & 0.002 & 0.385 \\
labor & 0.021 & 8.460 & 0.189 & 35.852 \\
investment & 0.007 & 2.941 & 0.000 & 0.013 \\
wage & & - & 0.010 & 1.929 \\
east & 0.051 & 20.114 & 0.141 & 26.766 \\
west & 0.050 & 19.671 & 0.005 & 0.889 \\
IMR & 0.016 & 6.382 & 0.024 & 4.579 \\
\hline
\end{tabular}

